\title{
ASSESSMENT OF SOCIO-ECONOMIC DEVELOPMENT OF SELECTED EUROPEAN COUNTRIES WITH THE USE OF A MODIFIED HDI
}

\author{
MAREK BIERNACKI ${ }^{\mathrm{a}, *}$, WOJCIECH GUZEK ${ }^{\mathrm{a}}$ \\ marek.biernacki@ue.wroc.pl,wojtek.guzekx@gmail.com
}

\begin{abstract}
a Wrocław University of Economics, Faculty of Management, Computer Science and Finance, Department of Mathematics and Cybernetics, Komandorska 118/120, Wrocław, Poland
\end{abstract}

\begin{abstract}
The aim of the paper is to analyse the socio-economic development of selected European countries represented by various social policies, and to verify the hypothesis of different speeds of development within the groups into which these countries divide. The following groups are considered in the analysis: Post-Communist countries (the Visegrad Group countries, Lithuania, Latvia, Slovenia and Estonia); Scandinavian countries (Denmark, Finland and Sweden); so-called welfare states and "Old Europe" countries (Germany, France, Spain and Italy along with Great Britain and Portugal); and "small but affluent" countries: (Austria, Switzerland and the Netherlands). For the measurement, a modified HDI index is employed, based on a number of sources, including the PISA (Program for International Student Assessment) assessment and the EHCI (Euro Health Consumer Index). The period of analysis covers the years 2006 - 2015. The analysis shows that GDP dynamics of PostCommunist countries is significantly higher than the other countries' dynamics. Dynamics of social development measured by HDI is also more rapid compared to the other groups. However, dynamics measured by the modified HDI does not give a clear indication. Affluent and large European countries are not those with the most prominent socio-economic development. Speaking the language of physics, these countries have a big momentum, equal to the product of mass and speed, compared to other European countries.
\end{abstract}

\section{Key words}

Human Development Index, socio-economic development, Programme for International Student Assessment, Euro Health Consumer Index

\section{JEL classification}

A13, D6, I15, I25

\section{Introduction}

At a mini-summit of the heads of states of France, Germany, Spain, and Italy held in Versailles in March 2017, the German Chancellor Merkel fully expressed her endorsement of the view that 'we have come to a moment in the history of the European Union when a multispeed Europe is necessary; otherwise we are blocked' and that 'we must have the courage to accept that some countries can move forward a little more quickly than others'. This seems to raise an important question: is it viable to assume that these four countries can be seen as the European leaders of socio-economic development? To address this issue in depth, the author performed comparative analyses of socio-economic development dynamics of selected European states and examined their correlations for a period of $2006-2015$. The economic development should serve to support the social development, i.e. not only stimulate the increase of welfare and other social services, but also support the growth of human capital as a guarantee of further effective economic development. To address this issue in depth, the author performed comparative analyses of socio-economic development dynamics of selected European states and examined their correlations for a period of 2006 - 
2015. The economic development should serve to support the social development, i.e. not only stimulate the increase of welfare and other social services, but also support the growth of human capital as a guarantee of further effective economic development. Human capital in a population is comprised of people and their knowledge, skills, and health. For instance, in countries with already spacious support for education and science, further increase of such forms of support by $0.1 \%$ of the GDP will - in the long perspective $(20$ - 30 years $)$ - result in a GDP increase of ca. 1.5\% (Dougherty and Jorgenson, 1996). The findings indicate that expansion in education expenditure in developing countries affects per capita GDP positively, and the effect is not different from that of SSA countries (Appiah, 2017).

Safeguarding the socio-economic development of the human population, globally, is one of the main areas in the competence of the United Nations organisation. For this purpose, the formal framework of the UNDP (United Nations Development Programme) introduced the Human Development Index (HDI), a synthetic measure addressing each of the three key dimensions of human development: (a) long and healthy life, (b) knowledge, and (c) a decent standard of living. The HDI serves as basis for the annual UN reports of trends in the quality of life development between countries. From 2010, the three aspects of HDI measurements have been made on the basis of the following indices (UNDP, 2015): life expectancy at birth (a); expected years of schooling for persons aged 25 and older, and mean years of schooling for persons entering the education system (b), and per-capita gross national income (GNI) expressed in USD purchasing power parity (PPP \$).

The paper is organised in four sections. Following this introduction, Section 2 presents socio-economic data for selected 20 European countries, segmented into four groups; the section also includes a brief overview of methods employed in HDI calculations and a presentation of the postulated new measure (HDI*) supported by data from other industrystandard indices employed in each of the studied dimensions. Section 3 presents the results of $\mathrm{HDI}^{*}$ calculations together with analyses of correlations between HDI*, HDI, and per-capita GDP. The section includes comparisons of the 'social effectiveness' scores for selected European countries, calculated as the product of social welfare to cost. The last section of the paper provides conclusions and discusses directions for further studies in the area.

\section{Data}

Analyses were performed for 20 selected countries, including those of the Visegrad Group: Poland, Hungary, Slovakia and Czech Republic, and representatives of the 'first speed Europe': France, Spain, Germany and Italy. For a more complete picture, the list was expanded to cover other post-communist states: Lithuania, Latvia, Slovenia and Estonia and Nordic countries: Denmark, Finland and Sweden. The 'first speed Europe' group was expanded to cover Great Britain and Portugal, and another group of 'small but affluent' countries was added: the Netherlands, Austria, and Switzerland. For the lack of reliable data for the period under evaluation, the remaining countries of Europe were not included in the study. Evaluations of the level of economic development were performed using the classical GDP per capita approach, with data expressed in PPP. Both the postulated index of socioeconomic development and the standard HDI were calculated on the basis of evaluations taken in three key dimensions: education, health, and welfare. In the report „The measurement of economic performance and social progress revisited: Reflections and Overview" Joseph Stiglitz, Amartya K. Sen and Jean Paul Fitoussi stated that socio-economic development should be measured by all factors mentioned in the article. (Stiglitz, 2008) Measurements of the education systems were performed using standard PISA (Programme for International Student Assessment) evaluations and graduate employment rates. Since PISA surveys are performed every three years, this perspective was naturally reflected in the determination of the time frame employed in the study. 
Evaluations of the level of economic development were performed using the classical GDP per capita approach, with data expressed in PPP. Both the postulated index of socio-economic development and the standard HDI were calculated on the basis of evaluations taken in three key dimensions: education, health, and welfare. Measurements of the education systems were performed using standard PISA evaluations and graduate employment rates. Since PISA surveys are performed every three years, this perspective was naturally reflected in the determination of the time frame employed in the study. Evaluations of the 'health' dimension were performed using the standard Euro Health Consumer Index - EHCI, with relative values published by the Health Consumer Powerhouse annually for the entire EU area. The EHCI index, as an instrument designed to evaluate health care services provision from a patient's viewpoint, is accompanies in the study by the HLY index (healthy life years index), as a measure of healthy life expectancy. The last dimension - that of welfare - was evaluated using the abbreviated form of Sen's social welfare function, calculated on the basis of percapita disposable income and the Gini coefficient, and analysed against the risk-of-poverty thresholds. Data was obtained from the Eurostat.

For the evaluation of effectiveness increase in social welfare, per-capita cost was adopted per region, i.e. calculated as the product of GDP percentage share in education and normalised GDP value, and as the product of GDP percentage share in health care provision and normalised GDP value, as applicable. Cost values were obtained from the OECD database.

\subsection{Performance in education}

Comparisons of national education systems were performed based on results of international editions of the PISA (Programme for International Student Assessment) international surveys held every three years, coordinated by the Organisation for Economic Co-operation and Development (OECD) and designed to test competences (education equity) of 15-year-old students in key subjects of compulsory education. The PISA survey provides assessments in three key subjects, namely: reading literacy, mathematical literacy and scientific literacy. Table 1 presents PISA score averages for the analysed groups of countries.

Table 1: Average PISA scores in selected groups of countries

\begin{tabular}{ccccc}
\hline Group of countries & 2006 & 2009 & 2012 & 2015 \\
\hline Post-Communist & 49.55 & 49.45 & 49.77 & 49.09 \\
Old Europe & 48.59 & 49.45 & 49.70 & 49.62 \\
Scandinavian & 51.92 & 51.27 & 50.47 & 50.76 \\
Small affluent & 51.22 & 50.76 & 51.26 & 50.22 \\
\hline
\end{tabular}

Source: the authors using OECD PISA reports.

The use of human capital, particularly the human skills and knowledge, is a direct reflection of the adjustment between the education system and the labour market. University graduates are the best example of a population group particularly vulnerable to any maladjustments in this respect. Adjustment problems typically come as a result of technological progress and structural economic changes, a problem faced by nearly every EU Member State at present (Dolado, 2015). One of the most popular measures of this adjustment is the graduate employment rate - the corresponding values are presented in Table 2 . The rightmost column presents dynamics indices for the analysed period.

It may be worth noting that the most pronounced decrease of graduate employment rates was observed for countries of the Old Europe (at 9.3\%), with post-communist countries registering the least notable decrease (at 1.5\%). 
Table 2: Employment rates of recent graduates

\begin{tabular}{cccccc}
\hline Group of countries & 2006 & 2009 & 2012 & 2015 & Change 2015/2006 \\
\hline Post-Communist & 79.68 & 75.69 & 74.44 & 78.50 & 0.99 \\
Old Europe & 79.82 & 76.45 & 72.00 & 72.40 & 0.91 \\
Scandinavian & 84.00 & 82.43 & 82.67 & 81.03 & 0.97 \\
Small affluent & 90.27 & 89.17 & 88.50 & 86.57 & 0.96 \\
\hline
\end{tabular}

Source: the authors based on data from Eurostat.

\subsection{Performance in healthcare}

The Euro Health Consumer Index (EHCI), calculated and reported annually by Health Consumer Powerhouse since 2004, was used for assessing the effectiveness of national healthcare systems in Europe. The idea of the measurement is to assess the efficiency of healthcare service provision from a patient's viewpoint. In 2012, the assessment included five categories: 1. Patient's rights and information, 2. Waiting time for treatment, 3. Effects of treatment, 4. Scope and range of the provided services, and 5. Pharmaceuticals. There were a few or even a dozen or so subcategories distinguished in each category. Table 3 presents EHCI results and dynamics indices for the analysed period.

Table 3: EHCI scores by country group

\begin{tabular}{cccccc}
\hline Group of countries & 2006 & 2009 & 2012 & 2015 & Change 2015/2006 \\
\hline Post-Communist & 53.77 & 59.86 & 61.13 & 64.06 & 1.19 \\
Old Europe & 64.96 & 69.67 & 66.77 & 73.20 & 1.13 \\
Scandinavian & 68.22 & 76.73 & 78.30 & 80.80 & 1.18 \\
Small affluent & 72.58 & 81.53 & 79.27 & 86.13 & 1.19 \\
\hline
\end{tabular}

Source: the authors based on data from Eurostat.

Similarly to the results obtained from analyses of graduate employment rates, EHCI score dynamics were found at the lower end for countries of the Old Europe (with growth dynamics at $12.7 \%$ ), while the post-communist countries registered the most dynamic growth (at $19.2 \%)$.

Human well-being is, to a large extent, a function of good health. Moreover, health condition largely determines human performance at work and in education-related tasks. One of the most adequate measures of health condition is the healthy life years index (HLY). To a certain degree of simplification, it may be observed that - while the life expectancy index measures life longevity - the HLY index can be seen as a gauge of life quality (Jagger, 2008). Therefore, the authors decided to employ the HLY as a measure of general health condition in societies under study. Table 4 provides an overview of HLY scores and dynamics indices obtained in the study.

Table 4: Healthy life years in absolute value at birth

\begin{tabular}{cccccc}
\hline Group of countries & 2006 & 2009 & 2012 & 2015 & Change 2015/2006 \\
\hline Post-Communist & 55.89 & 57.59 & 58.25 & 57.41 & 1.03 \\
Old Europe & 62.43 & 61.54 & 62.68 & 62.79 & 1.01 \\
Scandinavian & 62.62 & 63.22 & 62.23 & 63.58 & 1.02 \\
Small affluent & 62.88 & 61.72 & 63.55 & 58.83 & 0.94 \\
\hline
\end{tabular}

Source: the authors based on data from Eurostat.

Again, dynamics of change in HLY were found to be the most favourable for postcommunist countries (a $2.7 \%$ increase), with the low end represented by the 'small but affluent' group of countries (a decrease of 6.4\%). 


\subsection{Performance in welfare}

Evaluations of social welfare were performed using Sen's abbreviated social welfare function $I S=\mu(1-G)$, where $\mu$-adjusted gross disposable income of households per capita in PPS, $G$ - Gini coefficient (Sen, 1973). Table 5 presents $I S$ scores and dynamics of social welfare development in the studied groups in the years $2006-2015$.

Table 5: Sen's abbreviated social welfare function

\begin{tabular}{cccccc}
\hline Group of countries & 2006 & 2009 & 2012 & 2015 & Change 2015/2006 \\
\hline Post-Communist & 7827.42 & 8824.67 & 9834.54 & 10909.64 & 1.39 \\
Old Europe & 13927.95 & 13914.30 & 14423.42 & 15351.80 & 1.10 \\
Scandinavian & 14333.97 & 15266.21 & 16797.22 & 17879.19 & 1.25 \\
Small affluent & 17071.84 & 17521.31 & 18683.25 & 19504.44 & 1.14 \\
\hline
\end{tabular}

Source: the authors based on data from Eurostat.

Over the analysed period, the highest rates of welfare growth dynamics were found in postcommunist countries (at 39.4\%), i.e. 29 percentage points in excess of the lowest rates (those for countries of the Old Europe).

The other index taken into account in the determination of social welfare was the share of people unburdened by the risk of poverty, calculated as "1" minus the at-risk-of-poverty rate. The at-risk-of-poverty rate is the share of people with an equivalised disposable income (after social transfer) below the at-risk-of-poverty threshold, which is set at $60 \%$ of the national median equivalised disposable income after social transfers. This indicator does not measure wealth or poverty, but low income in comparison to other residents in that country, which does not necessarily imply a low standard of living (Eurostat). Table 6 presents the recorded values of the index and the associated change dynamics.

In all of the analysed groups, the share of people unburdened by the risk of poverty was in decline, with the most favourable rates reported for post-communist countries (a $0.8 \%$ decline).

Table 6: The share of people unburdened by the risk of poverty

\begin{tabular}{cccccc}
\hline Group of countries & 2006 & 2009 & 2012 & 2015 & Change 2015/2006 \\
\hline Post-Communist & 83.76 & 84.15 & 84.63 & 83.11 & 0.99 \\
Old Europe & 82.87 & 82.93 & 82.60 & 81.93 & 0.99 \\
Scandinavian & 87.80 & 86.23 & 86.53 & 86.37 & 0.98 \\
Small affluent & 87.57 & 86.27 & 86.53 & 86.30 & 0.99 \\
\hline
\end{tabular}

Source: the authors based on data from Eurostat.

Table 7 presents average volumes of per-capita education and health care provision costs by country group. Costs were calculated as the product of GDP share assigned for education and health care and the per capita GDP expressed in purchasing power parity. The volume index of GDP per capita in Purchasing Power Standards (PPS) is expressed in relation to the European Union (EU28) average set to equal 100. If the index of a country is higher than 100, this country's level of GDP per head is higher than the EU average and vice versa

Table 7: Average total cost of education and public health care provision

\begin{tabular}{ccccc}
\hline Group of countries & 2006 & 2009 & 2012 & 2015 \\
\hline Post-Communist & 4.79 & 5.17 & 5.16 & 5.34 \\
Old Europe & 9.58 & 9.65 & 9.02 & 9.04 \\
Scandinavian & 12.31 & 12.77 & 13.16 & 12.83 \\
Small affluent & 13.50 & 14.00 & 14.00 & 13.93 \\
\hline
\end{tabular}

Source: the authors based on data from the OECD and Eurostat. 
As expected, the largest volumes of per capita expenses were found in the small affluent group of countries, followed by Scandinavian countries, the Old Europe, and with the postcommunist countries at the low end of the scale.

\section{Evaluation methodology, results and discussion}

The HDI index, despite being a well-established part of the UNDP framework, has long been subject to criticism (Desai, 1991). Neumayer (2001) provides a comprehensive overview of professional literature on alternative computational methods for calculating the HDI. There was proposed HDIF index which performs better than the current HDI. HDIF compromises both stock and flow variables. Hou et al. (2015) following the introduction of numerous programmes for the evaluation of education and health care systems in the early years of the 21st century, the natural evolution was to employ their results as basis for comparative analyses of socio-economic development across countries or groups of countries. The postulated HDI* can be seen as a general analogy to the present HDI, expressed as the geometric mean of indices representing the three key social aspects under evaluation.

The aspect of education is evaluated on the basis of two indices: average PISA score as a relative measure of knowledge and competences of persons aged 15 in countries of the OEDC area, and a normalised ratio of employment for university-level graduates.

$$
H D I^{*}=\sqrt[3]{E I \times H I \times W I},
$$

where

$$
E I=\frac{x+y}{2},
$$

where $x$ is country score average (PISA), $y$ is graduate employment ratio. The $H I$ was used for evaluation of the health care aspect, as an arithmetic mean of two indices: the standard $\mathrm{HCI}$, and a normalised HLY index.

$$
H I=\frac{z+t}{2},
$$

where $z$ stands for HCI score, and $t$ represents normalised HLY.

The social welfare aspect of evaluation was addressed using Sen's abbreviated social welfare function (Sen, 1973) and a normalised (to a 100) ratio of persons unburdened by the risk of poverty. Similarly to the above, the index is expressed as an arithmetic mean of two indices:

$$
W I=\frac{a+b}{2},
$$

where $a=\mu(1-G)$ is normalised to a value of 100 of Sen's abbreviated social welfare function, and $b$ is normalised ratio of people unburdened by the risk of poverty. Normalisation, in this case, involved division by maximum value, and multiplication by a value of 100 , namely:

$$
\frac{\text { value }}{\text { value } \max } \times 100 \text {. }
$$




\section{Results}

Tables 8 and 9 present results of HDI and HDI* calculations, respectively, for the analysed groups of countries, based on OECD data for the years under examination, together with the associated dynamics indices. Each year's values represent arithmetic means of values scored by individual countries in each group. Figures 1, 2, and 3 present plots of dynamics for HDI, HDI* and per capita GDP, respectively. Figure 4 presents plots of social function dynamics in the analysed groups of countries, calculated as the product of human capital value and the share of education and health care in total public expense.

Correlations between per capita GDP and HDI* values in the period of $2006-2015$ were as follows: 0.749 for post-communist countries, 0.602 for Scandinavian, 0.026 for the Old Europe, and 0.256 for the small affluent countries. KPSS test was performed to test stationarity of GDP, HDI and modified HDI time series and the result is that all these time series are level-stationary on significance level equal to 0.05 .

These findings may be seen as attesting to the relative power of national policies of social development (investments in human capital) in the studied groups of countries. It may safely be stated that the higher the correlation, the better served are the basic duties of the state in matters associated with social development.

Table 8: HDI values

\begin{tabular}{cccccc}
\hline Group of countries & 2006 & 2009 & 2012 & 2015 & Change 2015/2006 \\
\hline Post-Communist & 82.48 & 83.55 & 84.55 & 85.88 & 1.04 \\
Old Europe & 86.45 & 87.28 & 88.13 & 89.20 & 1.03 \\
Scandinavian & 90.20 & 90.13 & 91.33 & 92.33 & 1.02 \\
Small affluent & 89.00 & 90.63 & 91.83 & 92.37 & 1.04 \\
\hline
\end{tabular}

Source: the authors based on data from the OECD.

Table 9: HDI* values

\begin{tabular}{cccccc}
\hline Group of countries & 2006 & 2009 & 2012 & 2015 & Change 2015/2006 \\
\hline Post-Communist & 68.13 & 68.92 & 72.99 & 70.42 & 1.03 \\
Old Europe & 76.70 & 75.66 & 78.63 & 75.02 & 0.98 \\
Scandinavian & 79.96 & 80.47 & 83.26 & 81.12 & 1.02 \\
Small affluent & 84.17 & 84.07 & 85.10 & 83.16 & 0.99 \\
\hline
\end{tabular}

Source: the authors based on data from Eurostat.

Figure 1: HDI* dynamics

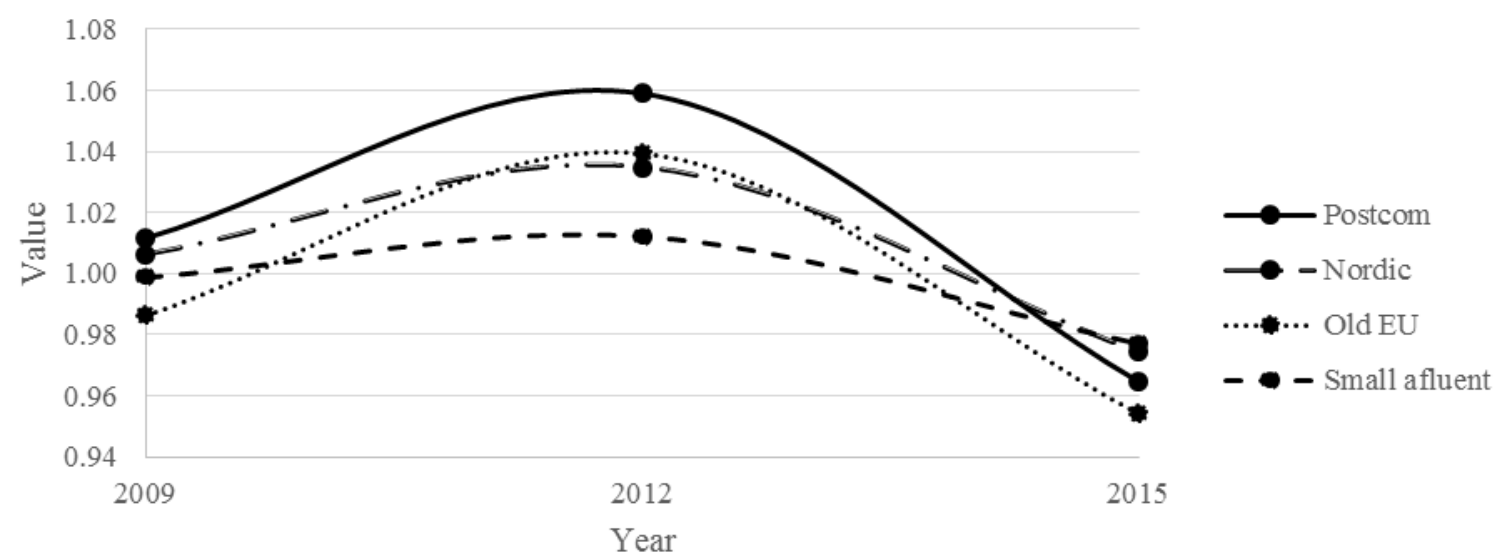

Source: the authors. 
Figure 2: HDI dynamics

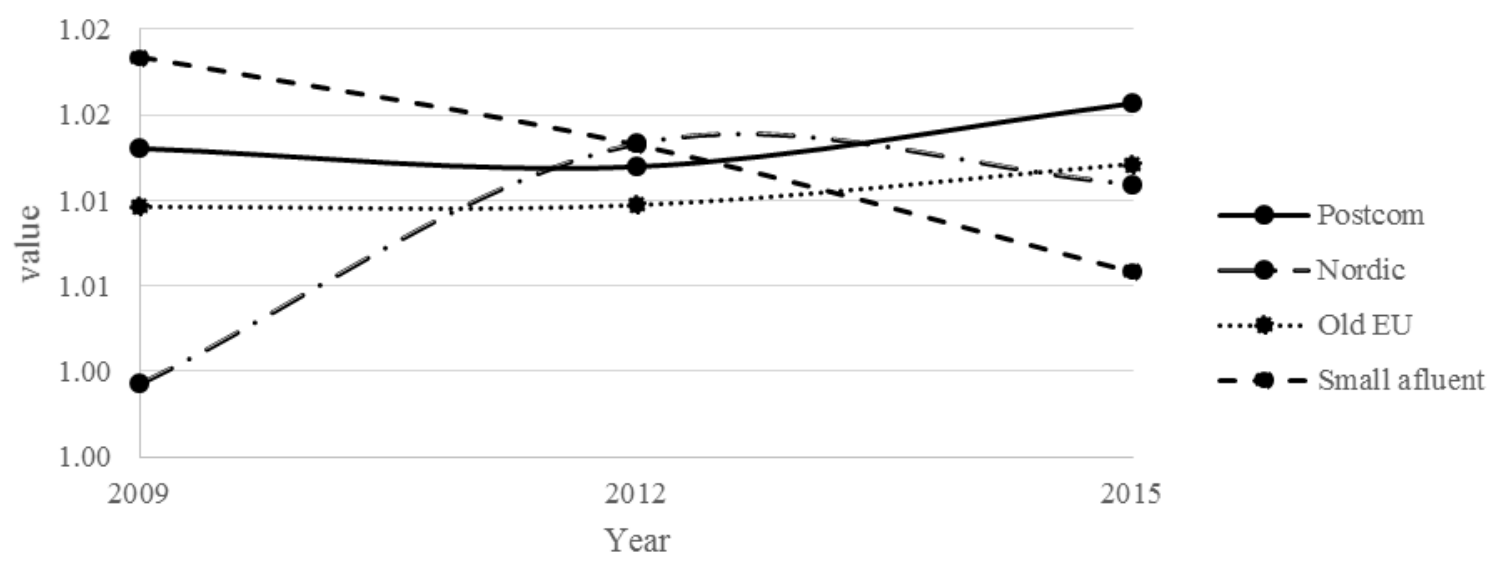

Source: the authors.

Figure 3: Per Capita GDP dynamics

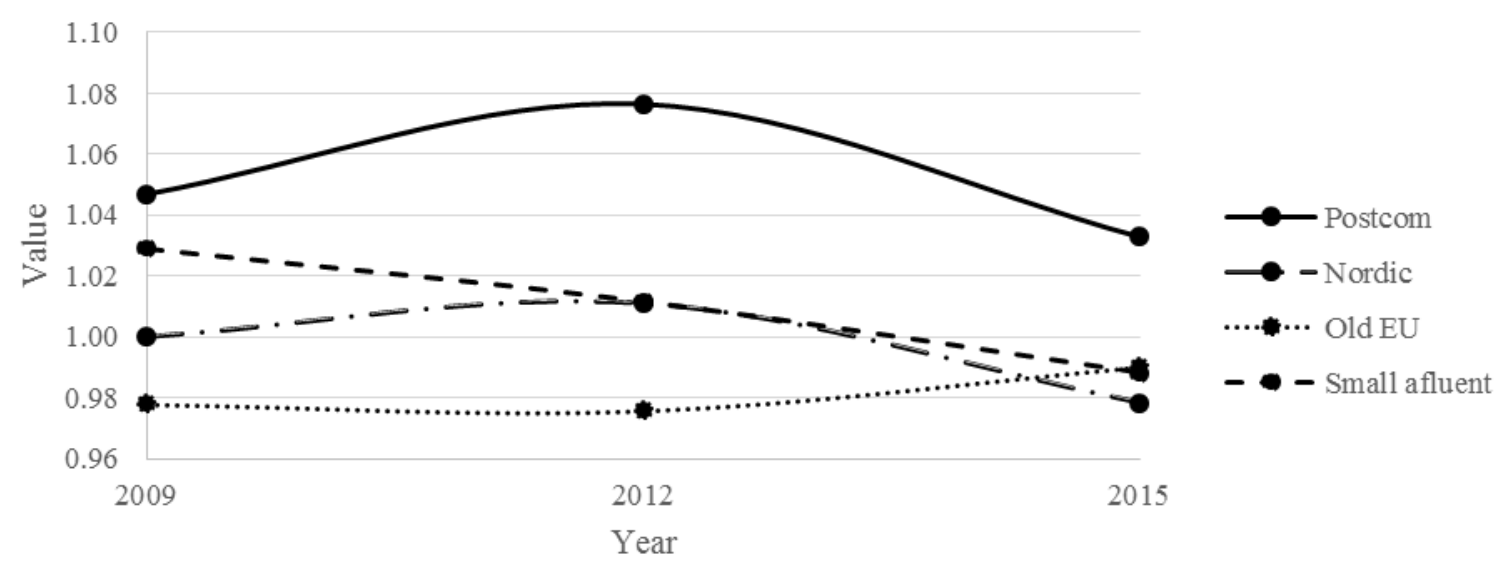

Source: the authors.

Figure 4: HDI*/cost

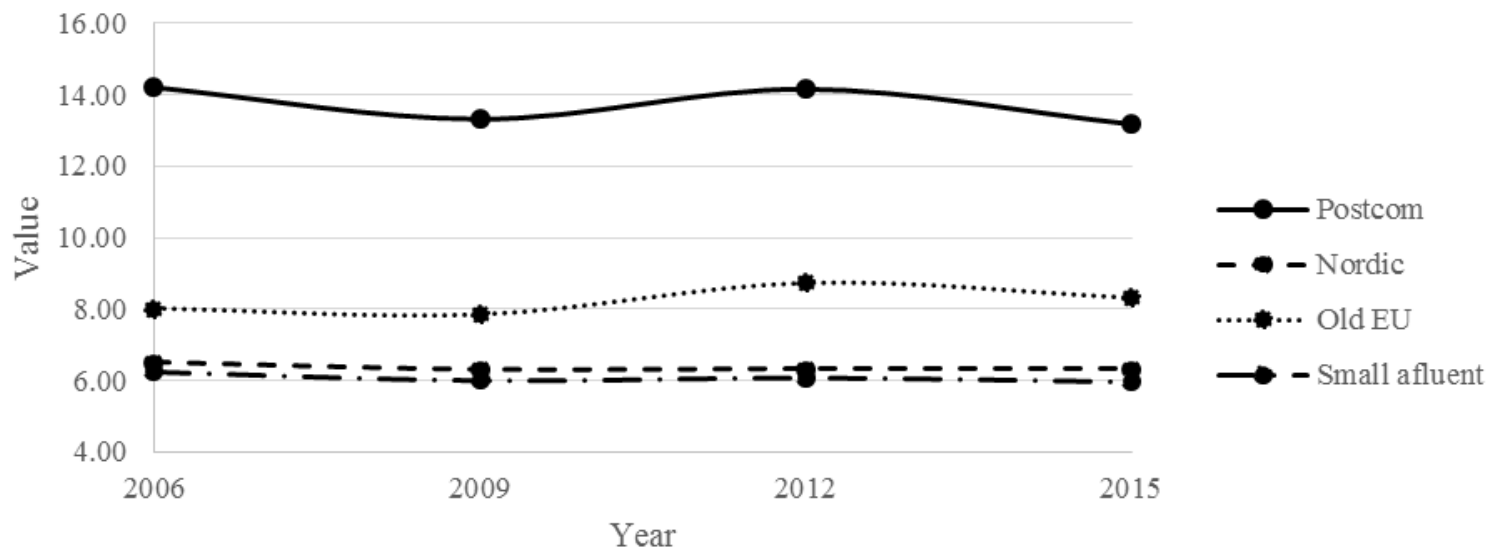

Source: the authors. 


\section{Conclusions}

Of all the groups under study, the per capita dynamics of GDP growth was found to be the highest for post-communist countries (Figure 3). However, while their respective HDI values remained clearly favourable compared to those reported for countries of the Old Europe (Figure 2), i.e. of large and affluent societies, no such clear distribution can be seen in comparisons of HDI* dynamics (Figure 1). In view of the above, the statement of Chancellor Merkel describing Germany, France, Italy and Spain as 'first speed' countries is ostensibly imprecise. If we address the problem at hand in terms of classical physics, we can describe the rich and affluent countries of the Old Europe as having high momentum (calculated as the product of the object's mass and velocity). Thus, even at low speeds, their mass advantage (wealth) allows them to make use of the inertial force. Physicists have a rule for conservation of momentum which, for the sake of our argument, can be simplified to the following: it takes a lot of power to set a large mass in motion.

Analysing the above finding, it may be observed that countries of the former communist block are arguably more effective in supporting their socio-economic development compared to other groups of countries under study. In addition, and relative to other groups, their per capita GDP volumes are scarcer, resulting in a much stronger emphasis on both the economic and the social growth. Post-communist countries also seem to be more effective in utilising the resources at their disposal (human and physical capital), as attested by their high scores in human capital production effectiveness (Figure 4). Notably, the HDI* dynamics of development in the last of the analysed periods (2012 - 2015) has decreased in all of the analysed groups, despite the assuring statements from the European Economic and Social Committee (EESC) on the impending reforms designed to improve the well-being of EU citizens.

Further directions of enquiry on the subject at hand will involve the use of nonparametric Data Envelopment Analysis method (DEA) for the evaluation of 'social welfare production function', as basis for determination of the most effective 'social supporters' among the EU Member States and as fundament for identification of the most optimal patterns in the distribution of public education and health care expenditures. Preliminary calculations using the DEA output oriented method have already provided arguments in support of this paper's thesis that the most effective policies of social support can be observed in post-communist countries, with the affluent (both small and large) placing at the low end of the scale.

\section{References}

[1] Appiah, N. E. 2017. The effect of education on per capita GDP in developing countries. In International Journal of Economics and Finance, 2017, vol. 9, iss. 10. pp. 136-144.

[2] Desai, M. 1991. Human development: Concepts and measurement. In European Economic Review, 1991, vol. 35, pp. 350-357.

[3] Dolado, J. 2015. No country for young people? Youth labour market problems in Europe. London : Centre for Economic Policy Research, CEPR Press, 2015. ISBN 978-1-907142-85-7.

[4] Dougherty C., Jorgenson D. 1996. International comparisons of the sources of growth. In American Economic Review, 1996, vol. 86, iss. 2, pp. 25-29.

[5] Hou J. et al. 2015. The dynamics of Human Development Index. In The Social Science Journal, 2015, vol. 52, pp. 331-347.

[6] Jagger C. et al. 2008. Inequalities in healthy life years in the 25 countries of the European Union in 2005: A cross-national meta-regression analysis. In The Lancet, 2008, vol. 372, iss. 9656, pp. 2124-2131. 
[7] Neumayer, E. 2001. The human development index - a constructive proposal. In Ecological Economics, 2001, vol. 39, pp. 101-114.

[8] Sen, A. 1973. On ignorance and equal distribution. In American Economic Review, 1973, vol. 63, iss. 5. pp. 1022-1024.

[9] Stiglitz J., Sen, A. K., Fitoussi, J. P. 2008. The measurement of economic performance and social progress revisited: Reflections and overview. Paris : OFCE Centre de recherche en économie de Sciences Po, 2008. 63 pp.

[10] United Nations Development Programme (UNDP) 2015. Human development report 2015. New York : United Nations Development Programme, 2015. ISBN 978-92-1126398-5 